\title{
Galloping on
}

\author{
Stephen Hancocks OBE \\ Editor-in-Chief
}

The BDJ Upfront section includes editorials, letters, news, book reviews and interviews. Please direct your correspondence to the News Editor,

Kate Quinlan at k.quinlan@nature.com. Press releases or articles may be edited, and should include a colour photograph if possible.

$\mathrm{N}$ ot everyone considers history to be important or even of particular interest. Mention of it often

sparks thoughts of interminable attempts to memorise dates, places and people, of boring school lessons and dreary museum visits. Yet, there is value in being able to look back and analyse how and why things were and, by comparison, how and why they have influenced the pattern that is now.

Stanley Gelbier's article on Sir Wilfred Fish, in this issue, provides us with a comprehensive account of the life of one of the leaders of the dental profession in the UK in the last century. ${ }^{1}$ As importantly, it also gives a valuable insight into how dentistry was conducted and how dentists were regarded during the course of the last hundred years. The worth of such research is in encouraging us to pause and wonder about how different life was then and how people managed without various aspects of the technologically shaped lives we live now. The additional reflection it brings revolves around our ability to better understand where we are now because of where we were then. How to map those seemingly old-fashioned and unconscionable mores of a society long gone onto the stresses we endure and aspirations to improve that we now entertain.

When comparing Sir Wilfred's life with our own, and not intending any judgment whatsoever, there are probably few of us who have our own stables and ride out every morning before commuting to work. Some of us doubtless do, but I suggest that the expectation is less than it was previously. Similarly, the restful, domestic aura that suffuses the portrait of Sir Wilfred painted by his second wife (shown as Figure 2 in the paper) suggests a long-departed idyll of suburbia now consigned to television documentaries about the development of the Metropolitan Railway or the advent of Garden Cities. A small sherry before luncheon perhaps?

Yet these are the foundations laid down in the $20^{\text {th }}$ century on which the enduring structures of the profession were built. Sir Wilfred's life and career spanned the 1921 Dentists Act which established the legal basis on which we still practise, the creation of the GDC which still regulates us and the genesis of the NHS which still forms a central part of the delivery of dental care. However, during the same period, there were two world wars, and the equivalent of a revolution in society emerged in the form of hundreds of advances; women got the vote, homosexuality between men was decriminalised, legislation on discrimination was enshrined - fluoride was added to toothpaste.

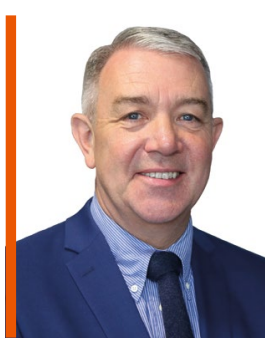

'Since the art and science of dentistry rely on a dual platform of treating people and patients, we have to factor these societal shifts [...] into our approach to our work.'

All of these changes have impacted on the lives that we lead as citizens and as professionals. Since the art and science of dentistry rely on a dual platform of treating people and patients, we have to factor these societal shifts as well as falls in caries, advances in periodontal research and growth in tooth whitening into our approach to our work. But we also have to consider the effect on the structure of the profession itself and perhaps in some aspects we have been slower to come to the realisation of this than we should in matters, for example, of equality, diversity and inclusion. Advances in some of these areas seem inexorable yet frustratingly slow to us. As Patricia Neville points out in her research paper, also in this issue, 'recent political events have put the issue of the ethnic diversity of the UK dental profession back into the spotlight ... while there is a "flow" of those from minority ethnic groups into the dental profession, their progression to specialism and clinical academia appears blocked.'

The importance of these two papers, juxtaposed by an accident of history itself, is that they raise our awareness of contemporary issues, spurring us to change them but also providing some of the background explanation enabling us to set them into a knowing perspective for pragmatic action. Despite the differences in the times of Sir Wilfred and the times of today, there is one aspect that I thought had a particular resonance of consistency. Having prestigious patients in his Central London practice, he used money earned from 